\title{
F.A.S.E.B. Abstracts
}

\section{(Abstracts of Some Papers Presented at the April 9-14, 1965, Meetings of the Federation of American Societies for Experimental Biology. Reproduced from Federation Proceedings, 24:2, Part 1.)}

ANDREWS, JAMES W., Jr., ROBERT K. WAGSTAFF and HARDY M. EDWARDS, Jr. (Poul. Sci. Dept., U. Georgia, Athens). Cholesterol Turnover in the Laying Hen.

Single Comb White Leghorn laying hens were given an oral dose of cholesterol4-C14 to study the turnover rates in the liver, egg, intestinal wall, plasma, and feces. Plasma, feces and tissue samples were extracted with chloroform-methanol $(2: 1)$ and counted in a liquid scintillation counter. Lipid $\mathrm{C}^{14}$ was assumed to be a measure of $\mathrm{C}$-14cholesterol. Plasma cholesterol was determined by the method of Zlatkis (J. Lab. Clin. Med. 41, 486) and specific activity was calculated. Plasma biological half-life of orally administered C14-cholesterol in the laying hen was found to be 60 hours. Between 24 and 120 hours the labelled cholesterol left the plasma at a constant rate. In liver, plasma and intestine the percentage dose of C14-cholesterol reached a maximum between 12 and 24 hours which was followed by a continuous decline. Cholesterol $\mathrm{C}^{14}$ level in egg and feces increased throughout the experimental period. The short biological half-life of plasma cholesterol in the laying hen, as compared to mammals, may be explained by egg cholesterol deposition. (Supported by USPHS grant AM06338 and NIH grant 5-K3-18, 411).

BLAMBERG, D. L., V. VASAITIS, A. A. KHALIL, E. H. BOSSARD and G. F. COMBS. (U. Maryland, College Park). Effect of Amino Acid Balance on Voluntary Food Intake, Weight Gain, Carcass Composition and Levels of Nitrogenous Blood Constituents in the Chick.

Chicks consumed similar amounts of diets varying in amino acid (AA) balance for one hour after fasting, but subsequent intake was markedly reduced with diets which were imbalanced by adding methionine or unbalanced by methionine removal. The time elapsing before consumption was resumed was related to degree of imbalance. Blood NPN was elevated when methionine-deficient diets were fed while no constant differences were observed in blood glucose levels. Intake was reduced as the level of a single AA (methionine or lysine) was lowered without changing the protein level or when the protein level was increased without changing the level of the first limiting AA. Addition of other than the first limiting AA also reduced food intake. At these reduced growth rates, voluntary energy consumption in relation to energy needs also was lower as reflected by carcass composition. These findings support the theory that excess of blood AA (or their metabolism) influence physiological appetite rather than a deficiency of the first limiting AA. Preliminary serum AA determinations indicate that the effective AA excesses may be relative rather than absolute. (Supported by a grant from NIH).

BOORMAN, K. NEIL and HANS FISHER. (Rutgers State U., New Brunswick, New Jersey). Is there a Specific Arginine-Lysine Antagonism for the Chick?

A specific antagonism between arginine and lysine in the chick has been postulated by Smith and Lewis (Proc. Nutr. Soc. 23:XXVIII, 1964) and by Jones (J. Nutr. 84:313, 1964). We have further investigated the specificity of the proposed interaction. Results confirmed that excess dietary lysine depressed growth 
on an arginine-deficient diet, whereas tryptophan, leucine, phenylalanine and threonine when added in proportion to the chick's requirement did not. On the other hand methionine also caused a growth depression. Excess arginine caused little or no growth depression on a lysine-deficient diet. Excess lysine produced severe growth retardation on a number of different diets ostensibly adequate in all amino acids. It appears that the proposed arginine-lysine antagonism is only a reflection of the non-specific detoxification effect of arginine.

BORGESE, T. A., and J. F. BERTLES. (Columbia U. and St. Luke's Hosp., New York, N.Y.). Ontogeny of Duck Hemoglobins.

Other investigators have reported that ducks have two distinct hemoglobins, a major $(\mathrm{Hb} \mathrm{I})$ and a minor ( $\mathrm{Hb} \mathrm{II})$ component. We have found a third hemoglobin (Hb III) demonstrable by electrophoretic and chromatographic methods, which is present in the duckling and which disappears in the adult (Fed. Proc. 23:500, 1964). In current work, analytical ultracentrifugation of duckling hemoglobin reveals that $\mathrm{Hb}$ III is not a polymeric artifact. Investigations with duck embryos demonstrate a fourth hemoglobin (Hb IV) which accounts for $70 \%$ of the total $\mathrm{Hb}$ per cell in the 7-day embryo, while the remaining 30\% is a single hemoglobin with electrophoretic characteristics identical to $\mathrm{Hb}$ III. In the 14-day embryo $\mathrm{Hb}$ IV is absent, the amount of $\mathrm{Hb}$ III has decreased from approximately 18 picograms at 7-days to approximately 8 picograms, and the adult hemoglobins (Hbs I and II) have appeared. Total $\mathrm{Hb}$ per cell increases during duckling maturation; this increase is exclusively in $\mathrm{Hb} \mathrm{I}$. The presence of $\mathrm{Hb}$ III in the duck embryo, its continued synthesis ( $\mathrm{Fe}^{59}$ incorporation in vivo) in the duckling, and its eventual disappearance bear resemblance to characteristics of fetal hemoglobin in the human. (Supported by N.I.H. Grant AM-08154).

BRAMBILA, S. and F. W. HILL. (U. California, Davis). Nutritional Properties of Reconstituted Triglycerides for the Chick.

Soybean oil fatty acids (SOFA) markedly depress growth of chicks (See F. W. Hill). Chicks fed diets in which the non-protein calories were supplied by soybean oil (SO) plus SOFA grew significantly faster than those fed diets based on SOFA with equivalent amounts of added glycerol. Growth was nearly maximum when SO furnished 2/5 of the lipid calories, indicating enhanced rate of absorption of SOFA facilitated by glycerides, and/or the presence in SO of an unidentified nutrient required by the chick under these conditions. The essential nutrient hypothesis was tested by comparing SO vs reconstituted triglycerides (RT) obtained by glycerolysis of purified SOFA methyl esters. Chicks fed diets high in RT exhibited retarded growth similar to chicks fed high SOFA diets; in addition, they exhibited incoordination and leg paralysis which affected all chicks within 3 weeks. Replacing $1 / 4$ of RT by SO significantly improved growth and prevented paralysis. FA from hydrolysed TR produced growth similar to SOFA, but no incoordination or paralysis. The observations with RT support the hypothesis of an essential nutrient lacking in RT and SOFA and required in high lipid diets; however, the possibility of a toxic, paralysis-inducing factor in RT cannot be excluded. (Supported in part by Rockefeller Foundation).

CAMPBELL, T. COLIN and LEO FRIEDMAN. (Dept. Nutr. \& Food Sci., M. I. T., Cambridge, Massachusetts). Metabolism of Chick Edema Factor.

Purified chick edema factor (CEF) concentrates have been shown to contain nine or more distinct gas chromatographic peaks. Wooton et al. (J.A.O.A.C. $45: 739,1962$ ) have isolated small amounts of three of these peaks. In a preliminary study, the unsaponifiable extract of a CEF-containing fat was force-fed to adult rats for 14 days at $2 \mathrm{cc}$. and $1 \mathrm{cc}$. per $\mathrm{kg}$. No gross pathology was noted except for slight weight depression and increase in liver weight. An assay for the active material based on electron-capture gas chromatography showed the presence in the unsaponifiable extract of all the peaks shown by a highly purified CEF material used as a reference standard. Assay showed that only two of these peaks were present in the rat liver. The feces showed the presence of all the other peaks as well as two new peaks with retention times slightly greater than those of the peaks found in the liver and in the toxic fat. These results indicate highly selective absorption of CEF components and metabolism of these substances by the liver. Comparable studies in chicks may throw light on differences in species susceptibility to CEF. (Supported by Grant No. Ef-00305-01 from USPHS). 
CHEN, PHILIP S., Jr, and H. BRUCE BOSSMAN. (Dept. Radiation Biol. U. Rochester, New York). Effect of Vitamins D and $A$ in Rachitic Chicks.

Crystalline vitamins $D_{2}$ and $D_{3}$ were administered daily (in doses ranging from $3 \mathrm{IU} /$ day Vit. D2 and $40 \mathrm{IU} /$ day Vit. D3 up to $40,000 \mathrm{IU} /$ day of either vitamin) to chicks on rachitogenic diet. Percentage bone ash, while a good indicator of antirachitic activity, was not a reliable indicator of the toxic effects because it levelled off at doses above $400 \mathrm{IU} /$ day Vit. $\mathrm{D}_{2}$ and the per cent. ash for Vitamin $\mathrm{D}_{3}$ levelled off at consistently higher values. Levels of serum calcium with both forms of Vitamin $D$ reached a plateau of about $16 \mathrm{mg} / 100 \mathrm{ml}$ with doses above 4,000 IU/day bur setum phosphorus fell at the higher Vitamin D dosages. Body weights and extracted bone (tibia) weights indicated that Vitamin D3 was more toxic than Vitamin $D_{2}$ by an order of magnitude, about the same as their antirachitic potencies. Essentially no tetracycline was taken up by bones of chicks given 40,000 IU/day Vitamin D3 whereas rachitic and lower-dose chicks showed good uptake. Interestingly, bones of certain Vitamin D groups exhibited two concentric rings with rather sharpiy different tetracycline uptake and correspondingly different microradiographic densities. A dose of 2500 IU/day of Vitamin A-acetate was able to prevent the deleterious effects of the rachitogenic diet. (Supported by U.S.A.E.C. contract).

CHERKIN, ARTHUR and EVELYN LEE-TENG. (California Inst. Technol., Pasadena). Interruption by Halothane of Memory Consolidation in Chicks.

Experiments in rodents suggest that learning requires about $20 \mathrm{~min}$. to consolidate into a condition that survives anathesia (thiopental, pentobarbital, ether). The kinetics of consolidation are important for hypotheses of memory formation. To study the kinetics we have used a simple model that gives a precise measure of consolidation time by utilizing one-trial learning and fast induction of anasthesia. We presented a 7-mm sponge lure soaked with n-propanol or water to day-old chicks; $72 \%$ pecked it within $10 \mathrm{sec}$. Chicks learned in one peck to avoid the propanol lure for 18 hours. The memory trace was abolished when anasthesia was given instantly after the peck but survived when anathesia was delayed 1.5 hours. Anasthesia was with 3\% halothane for five minutes. Induction took $0.4 \mathrm{~min}$. and recovery took two minutes. When the lure was presented again after 4 or 18 hours, the percentage of chicks which re-pecked (and chicks per group) were:

\begin{tabular}{|c|c|c|c|}
\hline & \multicolumn{2}{|c|}{ Anasthesia } & \multirow[b]{2}{*}{ No anasthesia } \\
\hline & Immediate & Delayed $1.5 \mathrm{hr}$. & \\
\hline n-propanol lure & $66 \% \quad(41)$ & $28 \% \quad(54)$ & $19 \% \quad(53)$ \\
\hline Water lure & $68 \% \quad(59)$ & $86 \% \quad(63)$ & $83 \% \quad(60)$ \\
\hline
\end{tabular}

With intermediate peck-anasthesia intervals, we find intermediate levels of avoidance. The method appears useful for determining the kinetics of memory consolidation. (Supported in part by USPHS Fellowship 1-F3-25, 443-01, NIMH).

CHRISTENSEN, D. A., M. C. NESHEIM and F. B. HUTT. (Cornell U., Ithaca, New York). Changes in Distribution of Tissue Amino Acids Associated with Genetic Differences in Requirement of Arginine.

Differences between two strains of White Leghorn chickens selected for low (LA) or high (HA) arginine requirement were reported (Nesheim, et al., Poultry Sci. 43:1346, 1964). As a preliminary step in determining differences in arginine metabolism, amino acid levels were measured in tissues of four-week-old chicks fed diets adequate or deficient in arginine. The levels of free threonine plus asparagine, proline and ornithine were markedly reduced in the plasma of chicks fed the arginine deficient diet, compared to chicks fed the adequate diet. When fed the same diet the two strains tended to have similar levels of free plasma amino acids. The HA strain, however, had consistently higher plasma lysine levels than the LA strain, particularly when chicks were fasted for four hours before blood samples were taken. Total free muscle amino acids were similar for both diets, although 
there was a marked increase in the threonine plus asparagine with the deficient diet. The most notable difference between strains fed the same diet was that at both levels of dietary arginine the HA strain had higher levels of free muscle ornithine than the LA strain. (Supported by NIH Grant Am 06850).

CLASSEN, L. J., FRANK PAGORIA and J. C. FRITZ. (Dawe's Labs., Inc., Chigaco, Illinois). Factors Affecting Pigmentation of Broilers.

Feeding a specific dietary level of xanthophyll (lutein) or other effective pigmenter does not always produce the same degree of pigmentation. Some factors which might affect pigmentation were studied with broiler strain chicks in batteries and in commercial type broiler houses. In most of the experiments the pigmenter used was petal meal from Tagetes erecta $L$. Pigmentation of the chicks was graded by visual comparisons with a standard after 4 weeks on the test diet. With increasing xanthophyll intake, pigmentation responded as a diminishing increment curve. Recognized variables included strain and individual bird variation, health, feed intake, biological availability of the pigmenter, and length of the test period. Antioxidants were effective only to the extent that they protected the dietary carotenoids in vitro and in vivo. Feeding lecithin had no effect on utilization of xanthophyll. Menadione, and to a lesser extent MSB, produced pigmentation, but only at high levels which depressed growth. Menadione had no effect on utilization of xanthophyll. Organic arsenicals had no effect alone, but did enhance pigmentation when fed with a xanthophyll source. 3-nitro-4-hydroxyphenyl arsonic acid had a greater effect than arsanilic acid. Feeding CuSO4 had no effect on pigmentation.

COUCH, J. R., Y. N. BAKSHI, J. M. PRESCOTT and C. R. CREEGER. (Poul. Sci., Texas A \& M U., College Station). Trypsin Inhibitor in Guar.

The presence of a growth inhibitor in guar gum has been reported by Vohra and Kratzer (1964) and by Anderson and Warnick (1964) in studies with chicks. Guar meal has been reported to contain a chick growth inhibitor (Bakshi, Creger and Couch, 1964) which appeared to be proteolytic in nature. The proteolytic inhibitor was extracted with phosphate buffer $(.02 \mathrm{M}$ at $\mathrm{pH} 7.5)$; the mixture allowed to stand at $5^{\circ} \mathrm{C}$ for six to eight hours with occasional shaking, then filtered. Denatured hemoglobin was prepared according to the method of Anson (1938). The spectrophotometric method of Northrop et al. (1948) was used for the trypsin assay. In the enzyme assay $5 \mathrm{ml}$ of denatured hemoglobin substrate was incubated with $1 \mathrm{ml}$ of a solution of crystalline trypsin (five min. at $37^{\circ} \mathrm{C}$ ). Five per cent. of TCA was added rapidly. Five $\mathrm{ml}$ of the TCA filtrate was added to $10 \mathrm{ml}$ water and the absorption coefficient of the solution determined at $280 \mathrm{mu}$. Trypsin activity was inhibited by the guar meal extract. Heating the extract for 60 minutes destroyed the ability of the extract to inhibit trypsin. Heating the meal with steam injection destroyed the inhibitor.

DUNKELGOD, K. E., P. E. WAIBEL, D. C. SNETSINGER and R. J. SIRNY. (Inst. Agric., U. Minnesota, St. Paul). Studies of the Relationship between Plasma Free Amino Acid Levels and Dietary Requirements of Turkeys.

Free plasma amino acid levels and growth rate were used as criteria in establishing an amino acid diet for turkey poults. The patterns of amino acids of Dean and Scott (Poultry Sci. 42:1264, 1963) and Snetsinger, Waibel and Fitzsimmons (Poultry Sci. $41: 1428,1962$ ) were examined at varying levels of dietary nitrogen. The former amino acid pattern at a protein-equivalent level of $25 \%$ of the diet (including $13.9 \%$ glutamic acid) produced a growth rate of $16 \mathrm{gm}$ per bird per day during 7-21 days of age as compared to $24 \mathrm{gm}$ for controls fed a stock diet. The replacement of two-thirds of the glutamic acid with glutamine or asparagine did not increase growth. Free histidine, tyrosine, and phenylalanine levels in the plasma were lower and glutamic acid, glycine and alanine levels were higher in the plasma of birds fed the amino acid diet as compared to those fed the natural stock diet. (Supported by USPHS Grant AM-06910).

EHRENSPECK, GERHARD and ROSEMARY SCHRAER. (Dept. Biophys., Pennsylvania State U., University Park). Calcium Transport by the Isolated Shell Gland of the Domestic Hen.

The accumulation of calcium on the mucosal side of the shell gland of the domestic hen has been studied. Pieces of tissue were stretched over ends of plastic tubes, $2 \mathrm{~cm}$. in diameter, with the serosal surface outside and the mucosal surface 
inside the tube. Both surfaces were bathed in phosphate-free Tris-buffered Ringer solution at $\mathrm{pH} 7.45$ and $39^{\circ} \mathrm{C}$. $\mathrm{Ca}^{45}(0.4 \mathrm{mu} / \mathrm{ml})$ was added to the medium bathing the serosal surface. The medium bathing each surface was stirred by a continuous stream of oxygen. At $40 \mathrm{~min}$. interval $0.1 \mathrm{ml}$ aliquots were removed from both sides of the membrane. Ca45 appeared to accumulate at a linear rate on the mucosal side after an initial lag of about 40-60 minutes. Administration of ATP on both sides of the membrane increased the rate of calcium transport. Doubling the amount of ATP increased the rate by a factor of two. Increasing the concentration of calcium on the mucosal side by $35 \%$ did not depress the rate of transport. This system, when undergoing oxidative metabolism, appears to be capable of transporting calcium against a concentration gradient in vitro and may be useful in studying the mechanism of calcium transport. (Supported by USPHS Grant De-01764).

FERGUSON, T. M., F. A. GOLAN and J. R. COUCH. (Texas A. \& M. U., College Station, Texas). Effects of Vitamin and Antibiotic Injections on the Chick Embryo.

Injections of $0.1 \mathrm{ml}$ of solutions containing folic acid, $2.5 \mathrm{mg}$; niacin, $2.5 \mathrm{mg}$; Ca pantothenate, $5.0 \mathrm{mg}$; aureomycin $\mathrm{HCl}, 2.5 \mathrm{mg}$, penicillin $\mathrm{G}, 10 \mathrm{mg}$; or streptomycin SO4, 12.5 mg were made into developing chick embryos after six days of incubation. Control eggs were injected with $0.1 \mathrm{ml}$ of sterile water or were neither drilled or injected. Eggs were replaced in the incubator and the effect of treatment on hatchability was determined. Hatchability of non-injected eggs was $100 \%$ and $91 \%$ in the eggs injected with sterile water. Hatchability of eggs from other treatments was as follows: niacin, 95\%, penicillin, 95\%; streptomycin SO4, 81\%; Ca pantothenate, $76 \%$; folic acid, $71 \%$; and aureomycin, 35\%. Embryonic mortality in the aureomycin group occurred primarily in the third week of incubation with edema in the neck region and malposition of embryos as the major gross effects.

FITZSIMMONS, R. C. and P. E. WAIBEL. (Dept. Poul. Sci., U. Minnesota, St. Paul). Metabolic Interrelationships of Glutamic Acid, Ornithine and Proline in the Chick Embryo.

Whole chick embryos ten days of age were analysed for 19 amino acids and urea one and four hours after I. V. injections of L-glutamic acid-U-14C, L-ornithine${ }^{5-14} \mathrm{C}$, or L-proline-U-14C. ${ }^{14} \mathrm{C}$ from L-glu appeared only in urea and aspartic acid. ${ }^{14} \mathrm{C}$ from L-orn appeared only in the urea, aspartic acid, glutamic acid, proline, $\mathrm{OH}$-proline, and arginine. ${ }^{14} \mathrm{C}$ from L-pro appeared only in urea, $\mathrm{OH}-$ proline and glutamic acid. It seems from these data that orn is not synthesized from L-glu or L-pro by the chick embryo. Citrulline, labelled or unlabelled, was not detected, indicating that its synthesis from L-orn may not occur in this system. This is in agreement with the results of Tamir and Ratner (Arch. Biochem. Biophys. $102: 249$, 1963) who found that carbamoylphosphate synthetase was lacking in chick liver and kidney. The fact that arginine and urea, but not citrulline, contained ${ }^{14} \mathrm{C}$ from ornithine suggests that there are mechanisms other than the ornithine cycle by which arginine and urea are synthesized in the chick embryo. (Supported in part by USPHS grants HE-04177 and AM-06910).

FLICK, D. F. and ROGER O'DELL. (Div. Nutr., Food \& Drug Admn., Washington, D.C.). Treatment of Chick Edema Disease with Oral Diuretics.

The following diuretics were fed to chicks along with a toxic fatty material (TFM) known to produce the chick edema disease (CED); diuril, aldactone, ammonium chloride, urea and ethacrynic acid. Weight gains, edema formation and blood levels of hematocrit, hemoglobin. erythrocyte sedimentation rate (ESR) and plasma total proteins and protein fractions were determined. Ethacrynic was the most protective against CED followed closely by diuril. Aldactone and ammonium chloride were least protective. Weight gains were lower when diuretics were fed than when not fed. Hematocrit values were lowered by CED but remained nearer to normal with oral diuril than any other diuretic. ESR was increased by the disease but remained near the normal range with diuril. Hemoglobin levels were similar to hematocrits. Thus, the results indicate that the chick edema disease may be at least partially prevented by feeding oral diuretics, particularly diuril and ethacrynic acid.

FRANK, F. R. and F. W. LORENZ. (Dept. Animal Physiol., U. California, 
Davis). Effect of Respiratory Acidosis on Calcification of the Egg Shell of the Domestic Fowl.

Laying hens were exposed to atmospheres containing regulated levels of carbon dioxide in a $5^{\prime} \times 5^{\prime} \times 12^{\prime}$ chamber equipped with ten cages, automated lights and waterers, a ventilating fan and controlled humidity. Carbon dioxide tensions were increased at regular intervals from $5 \mathrm{~mm}$ to $48 \mathrm{~mm}$ over a 21-day period and then maintained at $48 \mathrm{~mm}$ for 21 days. Arterial blood samples were drawn at the end of the six-week period. $\mathrm{PaCO}_{2}$ and $\mathrm{pH}$ were determined and compared to control values. An uncompensated respiratory acidosis was observed: pH 7.48 and 7.40, (HCO3) 20.8 and $21.2 \mathrm{mM} / 1, \mathrm{PaCO}_{2} 28 \cdot 3$ and $34.9 \mathrm{~mm}$ for control and $2.5 \% \mathrm{CO}_{2}$ atmospheres, respectively. Unlike metabolic acidosis induced by feeding $\mathrm{NH}_{4} \mathrm{Cl}$, in which shell thickness and egg weight decreases, shell thickness increased by an average of $8 \%$, egg weight by $3 \%$ at $2.5 \% \mathrm{CO}$. Therefore, blood $\mathrm{pH}$ per se cannot be implicated in the regulation of shell calcification. This report is the first known to our group of a treatment which increases calcification of egg shells. (Supported, in part, by NIH Graduate Training Grant No. GM 646).

FUJI, HIROSHI and N. K. JERNE. (U. Pittsburg Sch. Med., Pennsylvania). Morphological Studies of Plaque-Forming Cells of the Chick Spleen in Primary Response.

Certain spleen cells release hemolytic antibody to sheep red cells (SRC) and form plaques in agar. The plaque forming cell (PFC) in the center of each plaque can be studied morphologically by direct neutral red-Janus green supravital staining. Normal two, four and eight weeks old White Leghorn chicks have a total spleen about 10,150 and 3,000 PFC, respectively. During three days after one large i. v. dose of SRC, the number of PFC per spleen rises two to five thousand-fold and then levels off. The most rapid increase, about 50-fold, occurs during 24 hrs. between days one and two. The majority of PFC in normal four-weeks old spleens are mature plasma cells (plc.). Following SRC injection, PFC identified as immature plc. and blast cells increased rapidly during the first two days, less rapidly until day three, then gradually declined, whereas PFC identified as mature plc. increased rapidly between day one and day three and represented $83 \%$ of the PFC observed at day six. Round PFC of 6 to $7 \mathrm{u}$ in diameter and presenting a refractile cytoplasm were found in $20 \%$ of plaques from normal spleens as well as early after stimulation, but less frequently by days three and six. (Supported by NIH Grant AI 0637).

GLICK, BRUCE. (Poul. Sci. Dept., Mississippi State U., State College). Embryonic Exposure to Testosterone Propionate will Adversely Influence Future Mating Behavior in Male Chickens.

In 1961 we reported that the reproductive behavior of two male chickens hatched from eggs dipped in ethyl alcohol solutions containing two per cent. testosterone propionate (TP) was adversely affected (Poultry Sci. 40:1408). Ten additional males from eggs so treated have been studied. The excessive mortality of TP males (45 to $75 \%$ mortality to eight weeks of age) restricts the number available for study. Under natural mating conditions only one of ten such males successfully fertilized hens. On the other hand, semen from three of four TP males when artificially inseminated into hens successfully fertilized eggs. The testes of those TP males examined exhibited spermatozoa. A study of the mating behavior of ten TP males revealed that nine such males failed to mate with hens. A hormonal imbalance or defective neural mechanism might explain the TP males failure to mate. (Supported, in part, by NSF Grant GB-188).

HILL, F. W. and S. BRAMBILA. (U. California, Davis). Properties of High Lipid Diets Based on Free Fatty Acids.

Simplified diets based on isolated soybean protein (32\% of calories) deriving all non-protein calories from soybean oil (SO) support essentially normal growth in chicks. Compared to a control high glucose diet they produce slight hypoglycemia, moderate ketonemia, reduce liver glycogen by $60 \%$ but do not affect total blood lipid level. In contrast, a diet based on soybean oil fatty acids (SOFA) produces severely retarded growth, marked hypoglycemia and ketonemia and reduces liver glycogen to under $10 \%$ of the control. Feeding fatty acids as methyl or ethyl esters did not improve these conditions. Similar results were obtained with SOFA prepared either by alkaline or acid hydrolysis, and with oleic acid. Hypoglycemia and ketonemia were alleviated and growth improved by $6 \%$ glucose 
calories, apparently the minimum carbohydrate requirement. Higher levels of glucose further improved growth rate, but even at $45 \%$ of diet calories glucose did not overcome retardation by SOFA, indicating a limitation unrelated to carbohydrate. As added glucose over the range of 3-18\% of calories increased growth and food intake, SOFA intake was nearly constant, suggesting that rate of SOFA utilization limited food intake. Three limiting effects of SOFA diets are postulated: carbohydrate deficiency, rate of fatty acid utilization, and possible need for an unrecognized component of SO.

KIENHOLZ, E. W., C. F. NOCKELS and L. C. JACOBS. (Colorado State U., Fort Collins). Zinc Absorption in Adult Coturnix Quail.

Experiments were conducted with adult male Coturnix quail which had received a commercial-type diet prior to initiation of the assay. The assay included a 16-hour fast, then oral dosing of the birds with treatment solutions having a small amount of $\mathrm{Zn}-65$. Radiation from each bird was measured one hour and 24 hours after the oral dosing by use of a whole body counter. After one hour measurement, the birds were again given access to their previous diet. Comparison of the two radiation measurements from each bird provided the basis for estimating per cent. apparent absorption and retention. When the oral dose contained 0 and 500 ppm supplemental zinc as zinc chloride, birds absorbed 56 and 23 per cent. of the zinc, respectively. When the oral dose contained $5000 \mathrm{ppm}$ calcium as calcium carbonate, birds retained 47 per cent. of the zinc. This level of calcium did not affect zinc absorption when the doses contained $500 \mathrm{ppm}$ supplemental zinc.

KRATZER, F. H., ELLEN KRANTZ and FRAN VOHRA. (Dept. Poul. Husb., U. California, Davis). Interference of Certain Phosphates with Zinc Utilization.

Previous work has shown that several synthetic chelating agents improve the utilization of zinc for growth of poults fed a diet containing isolated soybean protein. The stability constants for zinc at $\mathrm{pH} \mathrm{7.4}$ determined by an ion exchange method were $2.20,5.22,5.05$ and 5.64 for orthophosphate, pyrophosphate, tripolyphosphate and hexametaphosphate, respectively. Similar values for effective chelating agents as EDTA and HEDTA were 6.45 and 6.25 at this pH. Hexametaphosphate, tripolyphosphate, pyrophosphate and phytic acid were found without effect in improving zinc availability in a low zinc diet. Hexametaphosphate and phytic acid depressed growth somewhat when added to a diet marginal in zinc but were not detrimental in a diet containing an excess of zinc. Tripolyphosphate depressed growth most severely in the marginal zinc diet and even slightly in the presence of excess zinc. (Supported by a Grant from the National Institutes of Nealth AMO5334).

KRISTA, L. M., P. E. WAIBEL, R. A. BALL, J. H. SAUTER and R. N. SHOFFNER. (Dept. Poul. Sci., U. Minnesota, St. Paul). Influence of Dietary, Hormonal and Genetic Factors on Blood Pressure of the Turkey.

Two strains of turkeys considered to have a high incidence and one strain considered to have a low incidence of aortic rupture were studied during $0-24$ weeks of age. Due to the sporadic nature of natural aortic rupture, the following treatments were employed: control diet, control plus $10 \%$ fat, control plus $0.01 \%$ beta-aminopropionitrile fumarate (BAPN), and control plus diethylstilbestrol (DES) injections. Blood pressure measurements were made when the birds were $15,16,17$ and 18 weeks of age using the indirect method. The strain considered to have a lower incidence of aortic rupture had a significantly lower systolic blood pressure of $223 \mathrm{~mm} \mathrm{Hg}$ as compared to the other strains having pressures of 245 and $240 \mathrm{~mm} \mathrm{Hg}$. DES injections lowered blood pressure significantly at each period with each strain. The average blood pressure for each treatment was: control, 246; DES, 214; BAPN, 244; and added fat, $241 \mathrm{~mm} \mathrm{Hg}$. Correlation coefficients of blood pressure to body weight were calculated, and no relation was noted. A low incidence of mortality was recorded throughout the experiment, with the exception of the DES treatment where one of the three strains suffered an increased incidence of aortic rupture. (Supported by USPHS Grant HE-04177).

LAUBER, JEAN K. and JAMES McGINNIS. (Washington State U., Pullman). Spectral Sensitivity of Avian Growth and Reproductive Processes.

Chicks were maintained from hatching under filtered incandescent light of 
several wave lengths. In one experiment continuous light (24L/OD) of four colors and white were compared with a diurnal (14L/10D) photoperiod. Wattage behind each plexiglass filter was adjusted from 40-200 watts to provide similar energy levels for all treatments. Growth was enhanced in green light, feed efficiency was poor in yellow and red. Yellow promoted eariy maturation of testes. The characteristic buphthalmos induced by continuous light was most extreme in blue light. Wavelength markedly affected behavior; blue and red light produzed the least excitable birds. In another experiment Leghorn chicks were reared under $16 \mathrm{~L} / 8 \mathrm{D}$ to 14 weeks, then $9 \mathrm{~L} / 15 \mathrm{D}$ to 18 weeks, $16 \mathrm{~L} / 8 \mathrm{D}$ thereafter. Intensity was 200 watts behind each of six filters. Females in green light reached reproductive maturity two to three weeks earlier than any other group, including controls (white light). Hens in yellow light laid slightly larger eggs. Fertility was impaired in red light but hatchability of eggs showed no spectral sensitivity. In most parameters a fraction of the spectrum had more effect than white light; thus some wavelengths may be inhibitory and others stimulatory. The results also suggest separate spectral optima for several photosensitive developmental and reproductive processes. (Supported by USPHS Grant NB-03770-20).

LEASE, J. G. (Clemson U., Clemson, South Carolina). Phytic Acid and Zn Availability of Autoclaved Sesame Meal.

Day-old chicks were fed untreated, two-hour, and four-hour autoclaved sesame meal. Untreated meal gave poor growth, severe leg deformities and low $\mathrm{Zn} / \mathrm{gm}$ bone ash. Two hour autoclaved meal resulted in a significant increase in weight; decreased leg deformities and increased $\mathrm{Zn} / \mathrm{gm}$ bone ash. Four hour autoclaved meal gave a significant increase in weight; a lack of leg deformities and an increased $\mathrm{Zn} / \mathrm{gm}$ bone ash which were comparable to untreated meal plus $60 \mathrm{ppm}$ of $\mathrm{Zn}$. Of the $1.4 \%$ total phosphorus, $1.0 \%$ was phytin phosphorus. Two hour autoclaving did not reduce this amount; four hour autoclaving reduced it to $\cdot 78 \%$. Thus the zinc of the four hour autoclaved meal was available to the chick in the presence of $78 \%$ of the original phytic acid. The prevailing theory has been that autoclaving freed $Z_{n}$ by destroying phytic acid in seed proteins. With this sesame meal, the chick was able to use zinc in the presence of the major part of the phytic acid in four hour autoclaved meal. This suggests that $\mathrm{Zn}$ phytate was freed from some bond in the meal and its zinc was available to the chick, or that $\mathrm{Zn}$ in sesame meal was held by something other than phytic acid, which was destroyed bv autoclaving. (Supported by NIH Grant AM 04742).

MATHIAS, M. M. and D. E. HOGUE. (Cornell U., Ithaca, New York). Effect of Selenium, Vitamin E and Antioxidants on the Incidence of Oxidative Diathesis in the Chick.

Previous work has shown Se and vitamin $\mathrm{E}$ very effective in the prevention of exudative diathesis (ED); however, conflicting results have appeared on the effectiveness of antioxidants. Chicks from an E-depleted flock were fed a $58.5 \%$ torula yeast basal diet during a depletion period and then assigned 0,20 and $40 \mathrm{ppb}$ $\mathrm{Se} ; 0$ and $5 \mathrm{ppm} \mathrm{E}$; and 0,100 and $300 \mathrm{ppm}$ ethoxyquin. An analysis of variance of percentage death and ED showed a highly significant $(P<0.001)$ protectiveness for $\mathrm{Se}$ and $\mathrm{E}$. For ethoxyquin the $\mathrm{F}$ was highly significant $(\mathrm{P}<0.001)$ for prevention of ED but less $(P<0.05)$ for prevention of death, because of the toxic effect of ethoxyquin. The statistical interactions as indicators of parallelism suggested a strong synergism between Se and E, a weak synergism between Se and ethoxyquin, and only additively between $E$ and ethoxyquin. An additional experiment incorporated 0 and $30 \mathrm{ppb} \mathrm{Se} ; 0$ and $200 \mathrm{ppm}$ ethoxyquin; 0,500 and $1000 \mathrm{ppm}$ DPPD. The antioxidants showed increasing protectiveness at $30 \mathrm{ppb}$ Se but not at $0 \mathrm{ppb}$ Se. Toxicity or death without signs of ED appeared on $200 \mathrm{ppm}$ ethoxyquin plus 1000 ppm DPPD and also on $500 \mathrm{ppm}$ ethoxyquin treatment, with or without Se. (Supported by a Grant from NIH).

McGINNIS, C. H. and R. K. RINGER. (Dept. Poul. Sci., Michigan State U., East Lansing). Arterial Occlusion and Baroreceptors in the Chicken.

Little information is available concerning the physiology of blood pressure regulation in the chicken. Occlusion of the carotid, vertebral and brachiocephalic arteries was carried out in commercial Leghorn-type hens to determine if functional arterial baroreceptors were present in the head, neck or carotid sinus regions. Bilateral carotid or vertebral artery occlusion produced little effect on blood pressure, heart rate or respiration. Occlusion of both the carotid and vertebral arteries 
resulted in a large, transient increase in blood pressure and a large, transient decrease in respiratory rate. These responses were obtained when the calculated cerebral perfusion pressure was decreased to 45 to $53 \mathrm{~mm}$. Hg. Neither the application of high pulsatile arterial pressure to the head nor drastic pressure changes in the area of the carotid sinus homologue (Brachiocephalic artery occlusion) produced any significant effect on systemic blood pressure or heart rate. The results of these experiments seemed to indicate that in the Leghorn-type hen systemic blood pressure responses due to carotid and vertebral artery occlusion are the result of cerebral ischemia and there is a lack of functional arterial baroreceptors in the areas of the neck, head and corotoid sinus homologue.

OLSON, GEORGE, W. J. PUDELKIEWICZ and L. D. MATTERSON. (Dept. Poul. Sci., U. Connecticut, Storrs). Nutritional Studies of Plant Lipids. 2. Isolation of a compound Inhibiting Tocopherol Deposition in Animal Tissues.

Bunnell, (Poultry Sci. 56:143, 1957) reported that the tocopherol content of alfalfa meal determined biologically was approximately one-third of that obtained by chemical means. More recently Pudelkiewicz and Matterson (J. Nutrition, $71: 143,1960)$ reported that the lipid extract of alfalfa depressed liver and plasma level of tocopherol in the chick. A series of fractionations of an alfalfa lipid extract have been carried out in an attempt to further purify the depressing factor(s). The separation procedures have included fractional precipitation, column, and thin layer chromatography. A material has been isolated by thin layer chromatography which will depress liver tocopherol content in the chick by approximately $35 \%$ when fed at a level of less than $005 \%$ of the diet. This material has been demonstrated to lose its tocopherol-depressing activity when either a decolorizing or saponification procedure is applied. Some physical properties of the compound will be presented. (Supported by Grant A5396 from the National Institutes of Health).

ORTEGA, L. G., A. A. KATTINE and B. O. SPURLOCK. '(Dept. Path., Emory U.. Atlanta, Geogia). Lympho-endothelial Interactions in the Developing Bursa of Fabricius.

The critical importance of the bursa of Fabricius in avian immunogenesis depends on a complex and highly specific interaction of lymphocytes and epithelial cells. Using light and electron miscroscopy, the visible expressions of this obligatory symbiosis have been studied between the tenth day of incubation and the third month posthatching. Typical lymphocytes were identified in bursal mesenchyme at day ten and they were numerous by the twelfth day at which time the bursal follicle is still wholly epithelial. Beginning on the fourteenth day, lymphocytes were observed transversing or impinging upon the epithelial basement membrane, a phenomenon of increasing prominence later in incubation and after hatching. In many instances lymphocytes were shown to be entering the medulla; we have not seen the reverse. Until the eighteenth day, mitoses were largely epithelial, but dividing lymphocytes form the major mitotic element by the nineteenth day. At this time degenerative changes in lymphocytes of the follicular center were also evident. We conclude that the epithelial cells do not differentiate into lymphocytes; that the early follicular lymphocytes are mesenchymal derivatives and later of mixed origin, and that lymphocytopoesis in the bursa provides cells which are utilized locally. (Supported by a Grant from USPHS).

OUSTERHOUT, L. E. and H. W. BRUINS. (Quaker Oats Res. Lab.' Barrington, Illinois). The Chlorine Requirement of the Chick.

Leach and Nesheim (J. Nutr. $81: 193,1963)$ reported $0-4$ week old chicks fed purified diets required $0.14 \%$ chloride. This has been interpreted to mean supplementary chloride is not needed in practical diets. The high sodium level when tetracycline antibiotics are potentiated with sodium sulphate causes watery feces, and has suggested that sodium chloride be eliminated, the chloride being supplied from other ingredients. Other studies using high efficiency, practical rations to produce market broilers have indicated that supplemental chloride is necessary for optimal growth and feed efficiency. Diets used contained only 0.07 to $0.11 \%$ chlorine. Performance was improved five to ten per cent. with the addition of 0.15 to $0.25 \%$ chloride in the form of sodium, potassium or ammonium salts, or mixtures of these. Review of the chloride content of common feedstuffs disclose that commercial fish meals contain from only $0.2 \%$ to as high as $2.4 \%$. Such ingredient variations should be considered before supplemental chloride is eliminated from practical diets. 
PETERSON, D. W. and A. L. LILYBLADE. (U. California, Davis). Effect of High Protein Diets on Body and Muscle Fat Content of Normal and Dystrophic Chicks.

Diets containing $24 \%, 45 \%$ and $78 \%$ protein were fed to normal chicks and to a strain of chicks with inherited muscular dystrophy characterized by high fat content of the pectoral muscle. Total body fat of both strains was reduced by the high protein diets but reduction in fat content of dystrophic muscle was affected only by the $78 \%$ protein diet. (Aided by NIH-NB).

PETERSON, R. D. A., B. R. BURMESTER and H. G. PURCHASE. (Ped. Res. Lab., U. Minnesota, Minneapolis). Visceral Lymphomatosis. A Malignancy of the Bursa-Dependent Lymphoid Tissue.

Visceral lymphomatosis (VL), a viral-induced lymphocytic malignancy of chickens, was previously demonstrated to be preventable by bursectomy in the first month of life (Peterson et al, 1964). The relationship of the bursa to this malignancy has now been further clarified. Chickens infected at time of hatching usually die of VL 5 to 9 months later. Bursectomy as late as three months almost completely prevents VL. Bursectomy as late as four or five months reduces the incidence of VL. Reimplantation of a young bursa in the peritoneal cavity either within or without a Millipore chamber did not reconstitute the chicken's capacity to develop VL. The thymus could not be implicated in this malignancy even by implanting embryonic thymus in bursectomized infected chicks, thymectomy or infecting the chickens during early embryonic life. Histologic studies demonstrate that $V L$ involves what we now consider to be the bursa-dependent lymphoid tissue of the chicken. These obversations support the two component concept of the lymphoid tissue by demonstrating a lymphocytic malignancy that is sharply limited to but one component. (Aided by American Cancer Society, American Heart Association, and National Foundation).

PUDELKIEWICZ, W. J., GEORGE OLSON and L. D. MATTERSON. (Poul. Sci. Dept., U. Connecticut, Storrs). Nutritional Studies on Plant Lipids. 1. Development of a Short Bioassay for Vitamin E.

While attempting to isolate a fat soluble plant substance which interferes with the absorption of tocopherol (Pudelkiewicz and Matterson, J. Nutrition $71: 143,1960$ ), it was found that a short bioassay was essential in order to follow isolation procedures. Twenty-four hour and 72-hour bioassays were developed which required only four tocopherol-depleted chicks per group and 150 and 350 grams of feed, respectively. Ten replicates of a standard tocopherol diet fed for a 24 or 72-hour period resulted in plasma tocopherol values of $1151 \pm 90$ and $1389 \pm$ $80 \mathrm{ug} / 100 \mathrm{ml}$ respectively and liver tocopherol values of $13.7 \pm 1.1$ and $18.2 \pm$ $1.4 \mathrm{ug} / \mathrm{g}$ respectively. Both of these bioassays gave the same relative results in initial isolation procedures. By use of the 72-hour bioassay, it has been shown that the liver tocopherol content was gradually lowered when d, alpha-tocopherol was added to diets containing increasing amounts of the alfalfa lipids. (Supported by Grant A5396 from the National Institutes of Health).

RAMP, W. K. and P. A. THORNTON. (Dept. Physiol., U. Kentucky, Lexington). Metabolic Response to Parathyroid Extract and Ascorbic Acid by Chick Bone.

Bone tissue from rachitic rats failed to show a metabolic response to PTE (Am. J. Physiol. 192:432). Work in this lab. (unpublished) suggested that ascorbic acid altered the activity of bone from vitamin $D_{3}$ deficient chicks. This study concerns the skeletal response by vitamin D deficient chicks to PTE and ascorbic acid. Cell nitrogen, glucose uptake, lactic acid output and \% ash were measured in the bone from controls, vitamin D deficient, and this deficiency state with ascorbic acid. All animals were injected daily with either saline or saline plus PTE (20 USP/100 gm body wt.) for two days. Each group exhibited a comparable reduction in cell nitrogen and an increased glucose uptake when PTE was injected. Little or no effect on ash or lactic acid output was evident. Injection of ascorbic acid to vitamin D deficient chicks effected a greater bone response, however. Cell nitrogen was elevated, glucose uptake and lactic acid output reduced and percentage ash significantly decreased. From these results it appears that chicks differ from rats in response to PTE and that ascorbic acid may play a role in the chick's bone cell activity. (Supported by a grant from NIH AM07724-01). 
SIMBONIS, S. and R. McBRIDE. (Dept. Pathol., Columbia U., New York, N.Y.). Pattern of Glycogen and Glucose-6-phosphate Activity in the Developing Chick.

Liver glucose-6-phosphate activity was estimated in embryos and chicks which were derived from crossing Barred Plymouth Rock and Rhode Island Red. Serial daily determinations were performed, commencing with the eight day embryo to six days posthatching. Analysis of whole liver homogenate $(755 \times \mathrm{g})$ demonstrated peak enzyme activity in 11 and 21 day old embryos (hatching). Differential centrifugation indicated that $80-90$ per cent. of the activity was in the $12,100 \times \mathrm{g}$ fraction from day eight to seventeen. At day seventeen the supernatant of the $12,100 \times \mathrm{g}$ fraction contained comparable activity and beyond this the stage the majority of activity was contained in this fraction. Enzyme activity and liver glycogen levels were inversely related. Triamcinolone, a potent stimulator of glucose-6phosphate in rats, and glucose-6-phosphate had no effect on enzyme activity when these substances were introduced into the albumen at day seven. (Supported by USPHS Grants GM-11847-02 and Am-08954-01) and HRC Grant U-1546.

SMIDT, M. J., FRANK PAGORIA and J. C. FRITZ. (Dawe's Labs., Inc., Chicago, Illinois). Choline and Methionine Requirements of Broilers.

Increased ration conversion requires re-evaluation of the nutrient levels in the feed. A series of feeding tests were made with broiler strain chicks in batteries and in commercial type broiler houses. Observations were made on weight gains, feed conversion, incidence of perosis, and condition of the carcass at the dressing plant. Better growth and feed conversion were obtained with higher than usual levels of dietary choline. With typical broiler diets $1650 \mathrm{mg} / \mathrm{kg}$ were needed for best performance. Varying dietary choline, within the limits studied, had little effect on carcass fat deposition or on characteristics of body fat. Increasing the dietary choline level above normal levels had no sparing effect on the methionine requirement, and dietary levels of choline chloride above $3300 \mathrm{mg} / \mathrm{kg}$ tended to depress growth. When the basal diet contained $0.21 \%$ cystine, a dietary source of cystine could spare methionine, but not when the basal diet contained $0.32 \%$ cystine. Optimum broiler performance required at least $0.48 \% \mathrm{dl}$-methionine for each $2200 \mathrm{Cal}$. productive energy per $\mathrm{kg}$.

STARCHER, BARRY and CHARLES HILL. (N. C. State, Raleigh, North Carolina). Studies on the Control of Ceruloplasmin in Chick Serum.

Ceruloplasmin, a copper-containing serum oxidase, is present in chicks under normal physiological conditions at a level of less than 1 I.U. (International Units; Rice, Anal. Biochem., 3:452, 1962) compared to $18 \mathrm{I}$.U. for sheep, or $50 \mathrm{I}$.U. for man, or 100 I.U. for swine. When chickens receiving a normal diet were infected with Salmonella gallinarum the ceruloplasmin level increased to $5 \cdot 40 \mathrm{I}$.U. by the fifth day after inoculation. In chicks receiving a copper deficient diet no increase in oxidase activity was observed. Further work showed that a non-infectious stressor such as subcutaneous injections of formaldehyde resulted in an increase in ceruloplasmin activity to 3.03 I.U. after 24 hours. That these effects were mediated through hormonal action was suggested by the finding that the administration of ACTH or hydrocortisone was followed by an increase in ceruloplasmin activity to 3.48 and 4.89 I.U. respect vely. Actinomycin D, $50 \mathrm{mcg}$., administered I.P. elevated ceruloplasmin activity to $6.31 \mathrm{I}$.U. A concimitant increase in serum corticosterone was observed following Actinomycin administration. Puromycin, 100 mcg. given I.P. did not significantly affect ceruloplasmin activity. (Supported by Grants from NiH).

TURK, D. E. (Clemson U., Clemson, South Carolina). Effect of Diet and Dietary Zinc Level on Liver Nucleic Acid Concentration.

It has been reported that Euglena developed decreased RNA content, doubled DNA content, and increased acid soluble amino acids when grown in a zinc deficient media. To test for this effect in higher animals, day old chicks were fed, for a 21 day period, semipurified diets based on casein and gelatin, isolated soybean, or sesame meal as the protein source. A diet containing each protein source was fed with no added zinc or with the following amounts of added zinc; casein: $20 \mathrm{ppm}$, isolated soybean protein; $60 \mathrm{ppm}$, and sesame; 60 and $120 \mathrm{ppm}$, to bring the total zinc level of these rations to adequate levels for each protein. Zinc deficiency symptoms; poor growth and feather and hock abnormalities, appeared in chicks fed all basal rations, but were not seen in zinc supplemented groups. Liver nucleic 
acids were isolated and separated into DNA and RNA, and the quantity of each determined. Dietary zinc level had no significant effect on liver content of either DNA or RNA. Nucleic acid content of fresh liver was greatest where the ration contained casein, intermediate with sesame meal, and least where soybean protein was used. Dietary protein source appeared to have more effect on liver nucleic acid content than did dietary zinc content.

WAGH, PREMANAND V. and PAUL E. WAIBEL. (Dept. Poul. Sci., U. Minnesota, St. Paul). Nutritional Effects of L-Arabinose and D-Xylose in Chicks.

Studies were accomplished to determine the nutritional effects of $L$-arabinose and D-xylose in chicks. These sugars were included in both natural and purified diets (substituting for D-glucose) at dietary levels of 10, 20 and $40 \%$. No effects on growth were noted at $10 \%$; however, at $20 \%$, xylose consistently suppressed growth and results with arabinose were inconsistent. Both pentoses depressed growth significantly at the $40 \%$ level. Analyses of various blood and tissue components indicated that: (1) increasing the dietary pentose levels resulted in an increase of total reducing sugars in plasma. Paper chromatography and glucose oxidase methods revealed that these increases were due solely to the pentoses. (2) Both liver and muscle glycogen were depleted with increasing dietary pentose levels; the depletion was more severe among the birds fed arabinose than those receiving xylose. (3) Plasma cholestrol level was significantly higher among birds fed $40 \%$ xylose. Liver and excreta lipids decreased with increased feeding of pentoses. (5) Total reducing sugars were higher in the excreta when the chicks received the dietary pentoses at 20 and $40 \%$ of the diet. (Supported by Min. Agr. Exp. Sta. Project 2315H).

WAGSTAFF, ROBERT K. and HARDY M. EDWARDS, Jr. (Poul. Sci. Dept., U. Georgia, Athens, Georgia). Requirement of the Chick for Arginine as Influenced by Essential Fatty Acid Deficiency.

Increasing levels of dietary arginine $(0, \cdot 2, \cdot 4, \cdot 6, \cdot 8 \%)$ were compared with increasing levels of dietary corn and cocoanut oils $(0,0 \cdot 5,1 \cdot 0,2 \cdot 0,4 \cdot 0 \%)$ added isocalorically in two $5 \times 5$ factorial experiments, replicated three times. Commercial male broiler chicks were used, and grams gain, feed efficiency and body composition were obtained after 3 weeks on the semipurified experimental diets. Arginine requirement as evaluated by gain and feed efficiency was about $0.54 \%$ added arginine (1.47\% total arginine) when diets contained at least $1 \%$ corn oil. With less corn oil the requirement appeared to be at least $0.8 \%$ added arginine $(1.69 \%$ total arginine). When coconut oil replaced corn oil the arginine requirement appeared to be at least $0.8 \%$ added arginine and was not reduced with increasing levels of coconut oil. Increased dietary fat tended to increase carcass fat at low levels of arginine and carcass fatty acid composition reflected dietary fatty acids. Increased dietary arginine tended to increase percentage carcass protein and decrease percentage carcass ash. (Supported in part by USPHS Grant AM-6338 and NIH Grant 5-K-18, 411).

WAIBEL, P. E., K. E. DUNKELGOD and R. C. FITZSIMMONS. (Dept. Poul. Sci., U. Minnesota, St. Paul). Determination of Amino Acids in Avian Blood Plasma using Column Chromatography.

The method of Hamilton (Ann. N.Y. Acad. Sci. 102:55, 1962) has been adapted to produce three "complete" chromatograms daily. Approximately $7 \frac{1}{2}$ hours are required per run at a pumping rate of $1.30 \mathrm{ml}$ per minute. Routine work is accomplished during an eight-hour working day by one person with the aid of a time clock which switches columns at midnight. In a standard mixture, the following ninhydrin-positive compounds are separated satisfactorily (in order of elution): cysteicacid, taurine, urea, hydroxyproline, aspartic acid, threonine, serine, glutamic acid, proline, glycine, alanine, alpha-aminobutyric acid, valine, cystine, methionine, iso-leucine, leucine, tyrosine, phenylalanine, gamma-aminobutyric acid, ammonia, ornithine, lysine, histidine, canavanine, and arginine. This system is used routinely for the determination of free amino acids in deproteinized blood plasma. One $\mathrm{ml}$ of plasma provides sufficient sample for two chromatograms. Recovery of amino acids is corrected by use of internal standardisation. With the present elution system, glutamine emerges with threonine and asparagine appears between threonine and serine. Asparagine produces its color maximum with ninhydrin at $440 \mathrm{mu}$. (Supported by USPHS Grant AM-06910). 